\title{
Chromosomal localization of the transcription factor YY1 in the mouse and human
}

\author{
W. Zhu, ${ }^{1}$ A.C. Lossie, ${ }^{2}$ S.A. Camper, ${ }^{2}$ D.L. Gumucio ${ }^{1}$ \\ ${ }^{1}$ Department of Anatomy and Cell Biology, University of Michigan, Ann Arbor, Michigan 48109-0616, USA \\ ${ }^{2}$ Department of Human Genetics, University of Michigan, Ann Arbor, Michigan 48109-0618, USA
}

Received: 29 September 1993 / Accepted: 29 November 1993

YY1 is a ubiquitously distributed transcription factor belonging to the GLI-Krüppel class of zinc finger proteins. The YY 1 cDNA was independently cloned in four different laboratories from human (Shi et al. 1991; Park and Atchison 1991) and mouse (Hariharan et al. 1991; Flanagan et al. 1992) tissues. Analysis of these cDNAs revealed that YY1 is highly conserved, showing $98.6 \%$ identity between the human and the mouse (Hariharan et al. 1991). Functionally, YY1 is an extremely versatile factor. It has been shown to be a negative regulator in some systems (Shi et al. 1991; Park and Atchison 1991; Lee et al. 1992; Bauknecht et al. 1992; Gumucio et al. 1992; Gualberto et al. 1992), and a positive regulator in others (Riggs et al. 1991; Hariharan et al. 1991). In some systems, the function of YY1 as an activator or a repressor is specified by the presence of other proteins (Shi et al. 1991). Finally, YY1 also binds to initiator elements and directs accurate basal transcription in vitro (Seto et al. 1991).

Previous studies had suggested the presence of a single $Y y l$ gene in the murine genome (Hariharan et al. 1991). The cloning and characterization of this gene was recently described (Sáfrány and Perry 1993). In this report, we utilized an interspecific backcross provided by The Jackson Laboratory, (C57BL/6J $\times$ M. spretus) $\mathrm{F}_{1} \times M$. spretus, to map the mouse $Y y 1$ gene.

A 396-bp human YY1 cDNA SmaI-HindIII fragment corresponding to amino acid residues 200-332 (Park and Atchison 1991) was used as the probe for Southern blot analysis. Within this region, there are only 17 nucleotide differences between human and mouse YY1 cDNAs $(96 \%$ homology). According to the genomic structure of murine YY1 (Sáfrány and Perry 1993), this fragment should detect exons 2 and 3 in their entirety and portions of exons 1 and 4 . The published restriction map of the mouse gene suggests that these exons should be present on four discrete genomic HindIII fragments. The fragment was labeled with the Random Primed DNA Labeling Kit (United States Biochemicals) and hybridized at $65^{\circ} \mathrm{C}$ to genomic DNA

Correspondence to: D.L. Gumucio blots. Restriction fragment length polymorphisms (RFLPs) between C57BL/6J and M. spretus were detected (data not shown). The $B g l$ II RFLP was selected for gene mapping (Fig. 1a). Genomic DNA samples from individual backcross progeny were then digested with BgllI and hybridized with the same probe at $65^{\circ} \mathrm{C}$. Analysis of the result unambiguously established the localization of the $Y y l$ gene on mouse Chromosome (Chr) 12 between DI2Mit5 and Igh$C$ (D12Mit8). With these and additional animals, the intergenic distances (cM) were calculated as $P m v-3-(14 \pm$ 4)-D12Mit5-(10 \pm 4$)-Y y I-(7 \pm 3)-I g h-C$ (Fig. 1b).

Considering the ubiquitous expression of the YY1 protein and its apparent functional diversity, the exact phenotype of a YY1 mutant would be difficult to predict, and pleotropic effects might be expected. Within the most likely interval for $Y y I$ localization (D'Eustachio 1993), only one uncharacterized murine mutation, twitcher $(t w i)$, has been described. Biochemical and phenotypical evidence suggests that the product of the twi locus may be a secreted product (Yeager et al. 1984), possibly a galactosylceramidase (Kobayashi et al. 1980). It thus seems unlikely that YY1 is the product of the twi locus.

The region to which $Y y l$ maps is part of an extensive linkage group $(35 \mathrm{cM})$ containing 17 genes whose homologs map to human Chr 14q (D'Eustachio 1991, 1992, 1993). To confirm the localization of YY1 on human Chr 14, we used the same probe to hybridize HindIII-digested genomic DNA isolated from a panel of human-mouse and human-hamster somatic cell lines. Five hybridizing bands of $19,6.5,6,3.5$, and $2.5 \mathrm{~kb}$ were detected in human DNA. Of these, the 19-, 3.5-, and $2.5-\mathrm{kb}$ bands were clearly localized on human Chr 14 (Fig. 2). These fragments probably represent the human homolog of the $Y y l$ gene on murine Chr 12. If so, this confirms the predicted localization based on mouse-human chromosome homology. However, the definitive localization of the human YY1 gene cannot yet be determined. The strongly hybridizing $6.5-\mathrm{kb}$ band was detected on human Chr 10. While this fragment may represent a duplicated YY1 gene or a YY1 pseudogene, the confirmation of this must await the cloning and characterization of the human YY1 gene. Finally, the more weakly hybridizing 6-kb band could not be mapped un- 


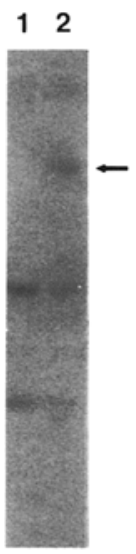

(a)
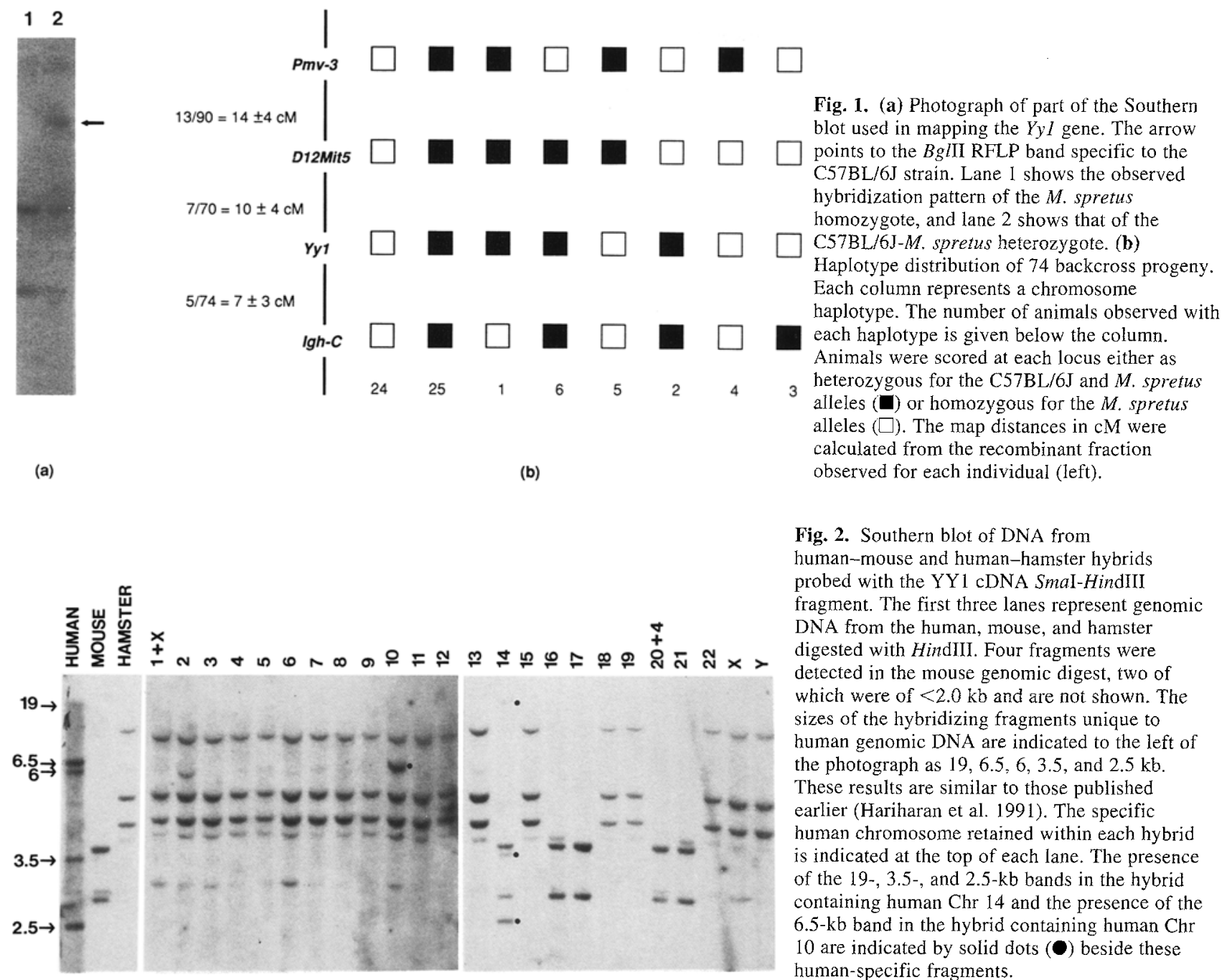

Fig. 2. Southern blot of DNA from human-mouse and human-hamster hybrids probed with the YY1 cDNA SmaI-HindIII fragment. The first three lanes represent genomic DNA from the human, mouse, and hamster digested with HindIII. Four fragments were detected in the mouse genomic digest, two of which were of $<2.0 \mathrm{~kb}$ and are not shown. The sizes of the hybridizing fragments unique to human genomic DNA are indicated to the left of the photograph as $19,6.5,6,3.5$, and $2.5 \mathrm{~kb}$. These results are similar to those published earlier (Hariharan et al. 1991). The specific human chromosome retained within each hybrid is indicated at the top of each lane. The presence of the 19-, 3.5-, and 2.5-kb bands in the hybrid containing human Chr 14 and the presence of the $6.5-\mathrm{kb}$ band in the hybrid containing human $\mathrm{Chr}$ 10 are indicated by solid dots $(-)$ beside these human-specific fragments.

ambiguously because it co-migrated with a restriction fragment from hamster DNA. These data thus suggest that the human genome may contain additional YY1 genes or pseudogenes.

Acknowledgments. We are very grateful to the staff of The Jackson Laboratory for the genomic DNA from the $(\mathrm{C} 57 \mathrm{BL} / 6 \mathrm{~J} \times$ M. spretus $) \mathrm{F}_{1} \times$ $M$. spretus backcross panel, Ms. Dean Turner of The Jackson Laboratory for information on D12Mit5 and DI2Mit8, Drs. Wayne Frankel and Verity Letts of The Jackson Laboratory for Pmv-3 typing data, and Dr. Peter D'Eustachio of New York University for providing a copy of the most recent mouse Chr 12 mapping report before publication. We wish to thank Dr. Miriam Meisler for helpful advice and for generously providing filters containing DNA from the human/rodent somatic hybrid cell panel, Dr. Michael Atchison of the University of Pennsylvania for kindly providing the human YYI cDNA clone, and Dr. Kenji Hayasaka for constructing the human YYl subclone used in the mapping. This work was supported by the National Institutes of Health Grant RO1HL48802 (DLG). The name, transcription factor $Y y /$ (YY1), has been approved by the chairs of the International Committees on Mouse and Human Genetic Nomenclature.

\section{References}

Bauknecht, T., Angel, P., Royer, H.-D., Hausen, H.Z. (1992). Identification of a negative regulatory domain in the human papillomavirus type 18 promoter: interaction with transcriptional factor YY I. EMBO J. $11,4607-4617$.
D'Eustachio, P. (1991). Mouse Chromosome 12. Mammalian Genome (Suppl.) 1, S192-S204.

D'Eustachio, P. (1992). Mouse Chromosome 12. Mammalian Genome (Suppl.) 3, S182-S194.

D'Eustachio, P. (1993). Mouse Chromosome 12. Mammalian Genome (Suppl.) 4, S176-\$191.

Flaganan, J.R., Becker, K.G., Ennist, D.L., Gleason, S.L., Driggers, P.L., Levi, B.-Z., Appella, E., Ozato, K. (1992). Cloning of a negative transcription factor that binds to the upstream conserved region of Moloney murine leukemia virus. Mol. Cell. Biol. 12, 38-44.

Gualberto, A., lePage, D., Pons, G., Mader, S.L., Park, K., Atchison, M.L., Walsh, K. (1992). Functional antagonism between YY1 and the serum response factor. Mol. Cell. Biol. 12, 4209-4214.

Gumucio, D.L., Heilstedt-Williamson, H., Gray, T.A., Tarle, S.A., Shelton, D.A., Tagle, D.A., Slightom, J.L., Goodman, M., Collins, F.S. (1992). Phylogenetic footprinting reveals a nuclear protein which binds to silencer sequences in the human $\gamma$ and $\varepsilon$ globin genes. Mol. Cell. Biol. 12, 4919-4929.

Harihaxan, N., Kelley, D.E., Perry, R.P. (1991). $\delta$, a transcription factor that binds to downstream elements in several polymerase II promoters, is a functionally versatile zinc figure protein. Proc. Natl. Acad. Sci. USA 88, 9799-9803.

Kobayashi, T., Yamanaka, T., Jacobs, J.M., Teixeira, F., Suzuki, K. (1980). The twitcher mouse: an enzymatically authentic model of human globoid cell leukodystrophy (Krabbe disease). Brain Res. 202, 479-483.

Lee, T.-C., Shi, Y., Schwartz, R.J. (1992). Displacement of BrdUrd-induced $Y Y 1$ by serum responsive factor activates skeletal $\alpha$-actin transcription in embryonic myoblasts. Proc. Natl. Acad. Sci. USA 89 , 9814-9818.

Park, K., Atchison, M.L. (1991). Isolation of a candidate repressor/acti- 
vator, NF-E1 (YY1, $\delta$ ), that binds to the immunoglobulin $\kappa 3^{\prime}$ enhancer and the immunoglobulin heavy-chain $\mu \mathrm{E} 1$ site. Proc. Natl. Acad. Sci. USA 88, 9804-9808.

Riggs, K.J., Merrell, K.T., Wilson, G., Calame, K. (1991). Common factor 1 is a transcriptional activator which binds in the c-myc promoter, the skeletal $\alpha$-actin promoter, and the immunoglobulin heavy-chain enhancer. Mol. Cell. Biol. 11, 1765-1769.

Sáfrány, G., Perry, R.P. (1993). Characterization of the mouse gene that encodes the $\delta / Y Y 1 / N F-E 1 / U C R B P$ transcription factor. Proc. Natl. Acad, Sci. USA 90, 5559-5563.
Seto, E., Shi, Y., Shenk, T. (1991). YY1 is an initiator sequence binding protein that directs and activates transcription in vitro. Nature 354 , 241-245.

Shi, Y., Seto, E., Chang, L.-S., Shenk, T. (1991). Transcriptional repression by YY1, a buman GLI-Krippel-related protein, and relief of repression by adenovirus E1A protein. Cell 67, 377-388.

Yeager, A.M., Brennan, S., Tiffany, C., Moser, H.W., Santos, G.W. (1984). Prolonged survival and remyelination after hematopoietic transplantation in the twitcher mouse. Science 225, 1052-1054. 